EESTI NSV TEADUSTE AKADEEMIA TOIMETISED. VIII KÖIDE
BIOLOOGILINE SEERIA. 1959, NR. 3

ИЗВЕСТИЯ АКАДЕМИИ НАУК ЭСТОНСКОИ ССР. ТОМ VIII

СЕРИЯ БИОЛОГИЧЕСКАЯ. 1959, № 3

\title{
KALLUSERAKKUDE TEKKE JA DIFERENTSEERUMISE TSOTOLOOGILIS-HISTOLOOGILISTEST ISEÄRASUSTEST
}

\author{
A. TOOMSALU, \\ bioloogiateaduste kandidaat
}

L. JÄRVEKULG

Idulehtedel on taime ontogeneesis suur bioloogiline tähtsus. Peale selle et nad on paljudel taimedel tagavaraainete panipaigaks, võivad opereeritud idulehed regenereeruda ja reprodutseerida terveid taimi. Kudede regenereerumine on organismile bioloogiliselt vajalik. Mitmesuguste juhuslike vigastuste korral sõltub organismi eksisteerimine rakkude regeneratsiooni intensiivsusest. Mida intensiivsemalt rakud taastuvad, seda rohkem võimalusi on organismi ellujạämiseks. Regeneratsioonivõime, olles organismile eluliselt vajalik omadus, on juba fülogeneesi jooksul välja kujunenud. Seepärast on idulehtede regeneratsiooniprotsesside uurimisel suur tähtsus. Nimetatud probleemi ei ole seni veel igakülgselt uuritud. Puudulikult on kảsitletud isoleeritud idulehtede rakkude tsütoloogilis-histoloogilisi muutusi ning kalluse rakkude teket ja diferentseerumist. Selletōttu on vajalik täpsemalt peatuda neil küsimustel.

Opereeritud idulehtede regeneratsiooni- ja reproduktsiooniprotsesse on uurinud paljud teadlased (Bonnet, 1779; van Tieghem, 1873; Blociszewski, 1876; Zabel, 1882; Simon, 1904; Smith, 1907; Михайлов, 1951, 1952, 1957a, 1957b jt.). Nad pöörasid tähelepanu idulehtedest arenenud taimede morfogeneesile.

H. Vöchting $(1878,1884)$ leidis, et pärast operatsiooni kattus idulehe lōikepind oorna kallusekihiga, mis oli veidi rohkem arenenud neis kohtades, kus idulehed kinnitusid lootevarrele.

Kalluse morfoloogilis-anatoomilist ehitust uuris E. Küster (1903). Ta kasvatas Padina pavonia talluse tükikesi merevees, kuhu oli lisandatud suhkrut. Nende tükikeste lōikepinnal tekkisid ebanormaalselt suured puhetunud rakud. Raku mahu suurenemist seletas Küster hüpertroofiaga - seejuures ta raku pooldumist ei näinud. Küster uuris ka ühe- ja kaheiduleheliste lehtede regeneratsiooniprotsesse. Cattleya mesofülli rakud venisid vigastuskohal pikaks. Ka neil objektidel ei täheldanud ta rakkude pooldumist. Suurenenud rakud muutusid hiljem väiksemaks ja klorofülliterad neis lagunesid, muid tsütoloogilisi muutusi ta ei märkinud. Küster uuris kalluse teket veel paplitel ja teistel puudel.

B. Němec $(1905,1911)$ oma uurimustes näitas, et mida kaugemal kasvukuhikust toimus kudede vigastus, seda nōrgemini nad regenereerusid. Ta leidis, et kallus arenes hästi pimeduses ja kōrges niiskuses.

Käesoleva töö eesmärgiks oli välja selgitada, kuidas tekkis kallus ja kuidas toimus rakkude diferentseerumine. Uurimine teostati Tartu Riikliku Olikooli geneetika ja darvinismi kateedri laboratooriumis 1956. ja 1957. aastal. Katsematerjalina kasutati päevalille Helianthus annuus L. sordi 'Saraatovi 169' idulehti. Päevalille seemniseid leotati 24 tundi vees, mille, temperatuur oli $18-20^{\circ} \mathrm{C}$. Seejärel lōigrati ära nende apikaalne ots 
2-3 mm kauguselt (joon. 1). Idu eemaldamine toimus küllalt sügava lôikega, mistõttu idulehtedele ei jäänud aktiivseid kasvukuhikulähedasi lootekudesid. Katsete teostamisel isoleeriti korraga 180 päevalilleseemnise idulehed. Iga katseseeria jaoks vōeti 30 seemnist, mis opereeriti žiletiga otseja kiillőikes (joon. 1, c) ning katteklaasiga otselōikes (joon. 1, a). Igast variandist asetati pooled valgusesse ( 8 tundi päevas luminestsentslampide valguses), pooled pimedusse (pidevalt). Katteklaasi kasutati selleks, et tekitada suuremat kudede vigastust. Idulehtede isoleerimine kiillōikes ei andnud erinevaid tulemusi otselōikest. Seetōttu käsitletakse siinkohal ainult otselôikes opereeritud idulehtede tsütoloogilis-histoloogilisi analüüse.

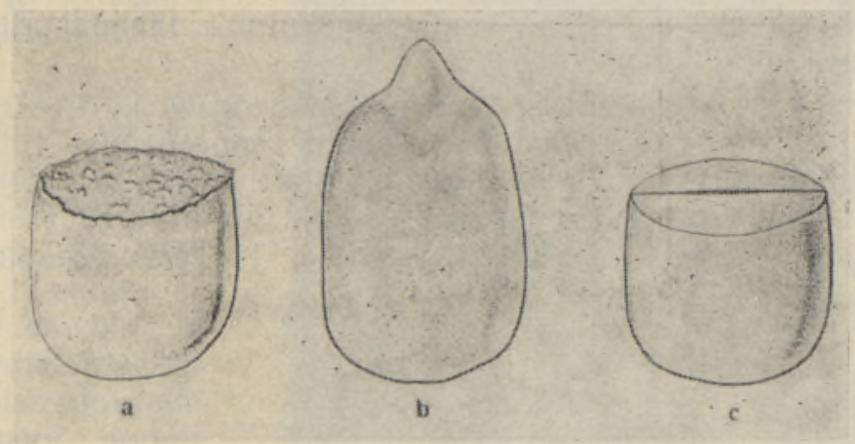

Joon. 1. $a-$ katteklaasiga opereeritud idulehed; $b$ - normaalne päevalille seemnis; $c$ - žiletiga opereeritud idulehed.

Päevalille isoleeritud idulehed pandi steriilsesse liiva, lōikepinnaga ülespoole. Neid kultiveeriti $15-25^{\circ} \mathrm{C}$ temperatuuril. Analüüse tehti nii ajutistel kui ka püsipreparaatidel. Esimesi valmistati 50, teisi 178. Tärklisesisalduse määramiseks mõjutati ajutisi preparaate J+JK-ga.

Töös rakendatud mikroskoopiline tehnika baseerub M. S. Navašini (1936) poolt väljatöötatud metoodikale. Fiksaatorina kasutati Navašini segu. Materjal fikseeriti iga 24 tunni järel hommikul kella 9-11. Lõikude paksus oli $8-10 \mu$. Preparaadid värviti Heidenhaini hematoksüliiniga.

Lõikepinna läheduses asuvate rakkude tsütoloogilis-histoloogilised analüüsid tehti kohe operatsiooni järel ja 10-12 tundi hiljem. Lõikudel nähti idulehe lõikepinnalähedaste rakkude vigastuses erinevat pilti, olenevalt sellest, kas seemnis lõigati žiletiga või katteklaasiga. Esimesel juhul oli lōikepind ühtlane ja sile. Isoleerimisel läbis žilett rakke ühel juhul keskelt või üldse sügavamalt, jättes järele vaid väikese osa rakust. Teisel juhul riivas žilett rakukesta või purustas ainult väikese osa rakust. Sellest olid tingitud erinevused lõikepinna rakkude taastumisprotsessides. Nõrgalt vigastatud rakk regenereerus hästi, kuid tugev vigastus kutsus esile lõikepinna rakkude hävimise.

Katteklaasiga opereerimisel oli kudede vigastus teistsugune. Nüri katteklaas muljus algul kudesid, hiljem rebis neid, mistōttu lōikepind oli konarlik. Lõikepinnalähedast ala läbisid mitmesuunalised muljutud rakkude read, kuna nende vahele oli jäänud terveid rakke. Sellise tugeva vigastuse korral regenereerusid lõikepinnalähedased koed aeglasemalt. Tôenäoliselt kutsus tugev vigastus esile sügavamaid muutusi raku füsioloogias ja nende taastumiseks kulus rohkem aega. Edaspidised kalluse arengu protsessid toimusid antud juhul samuti nagu žiletiga vigastamise 
korral. Pimeduses kasvavail idulehtedel võis pärast 24 tunni möödumist lõikepinnalähedastel tervetel rakkudel märgata, et tuumad olid veidi suurenenud, üksikuil juhtudel olid rakud lōikepinnast kasvanud natuke kõrgemale (mikrofoto 1). Eriti hästi nähti rakkude suurenemist ja vakuoolide teket lõikepinnalähedastel rakkudel alles 48 tundi pärast operatsiooni. Raku tugevama vigastuse korral voolas protoplasma ühes tuumaga välja. Preparaadil oli selgesti näha lõikepinnal surnud rakkude kesti, mis alles hiljem idulehe parenhüümrakkude ja juhtkoe rakkude pooldumisel kadusid. Raku nõrga vigastuse korral (kui lõige riivas raku kesta või protoplasmat) liikus tuum vigastuskoha lähedale ning tekkis uus rakukest taastus anatoomiliselt normaalne rakk. Sama nähtus esines ka valguses kultiveeritud idulehtede lõikepinna rakkudel. Neil aga märgati üksikute rakkude suurenemist, s. o. kasvamist, lõikepinna lähedal alles 3. või 4. päeval pärast operatsiooni.

Kahe järgmise päeva jooksul märgati pimeduses kultiveeritud idulehtede lõikepinnalähedastes rakkudes tuumade suurenemist (mikrofoto 2). Vigastuskohalähedased rakud värvusid intensiivsemalt, samuti oli neil tunduvalt vähem tärklisteri. Viimane asjaolu kinnitas B. Kabuse (1912),

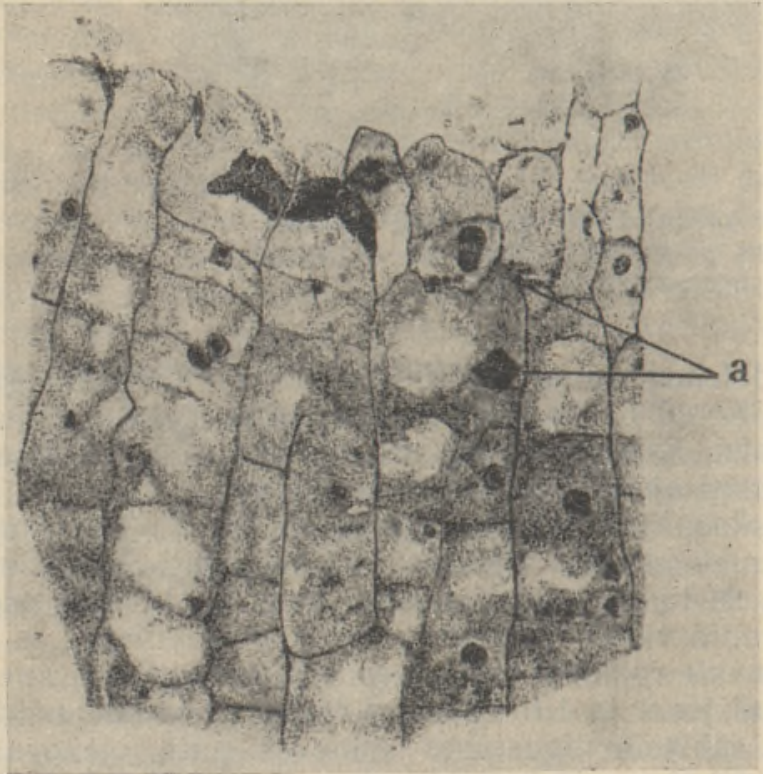

Joon. 2. Päevalille idulehtede parenhüümrakkude mitootiline pooldumine: $a-$ anafaasid. (Pikilöik.)

N. A. Maksimovi (1946)

jt. andmeid selle kohta, et rakkude vigastamisel intensiivistuvad hingamisprotsessid, mistõttu rakud kasutasid ära rohkem toitaineid.

Tsütoloogilis-histoloogilistel analüüsidel selgus, et pärast operatsiooni kadus mõnedc rakkude tuumadest tuumake, teistes rakkudes esines meta- või anafaas (joon. 2).

Pimeduses kasvatatud idulehtedel esines mitoosiprotsesse üksikuil juhtudel lõikepinnalähedasis suurenenud rakkudes 4, päeval pärast operatsiooni, tavaliselt aga veelgi hiljem (6. või 7. päeval). Samaaegselt märgati ka idulehe keskel, kaugel vigastusalast, juhtkoe ja epidermise lähedaste parenhüümrakkude mitootilist pooldumist. Seega suurenesid idulehed ka rakkude pooldumise arvel.

Rakkude pooldumisprotsessid olid tihedalt seotud nii opereeritud idulehtede kasvuprotsessidega kui ka kudede vigastuse füsioloogilise mõjuga. Rakkude pooldumisprotsessid ei toimunud kogu lōikepinna ulatuses üheaegselt. Kõige varem märgati mitootilist pooldumist just idulehe juhtkoe ja selle lähedastes rakkudes. Võis arvata, et juhtkoe enese ja tema ümbruses asuvad rakud olid füsioloogiliselt soodsamates tingimustes, mis põhjustaski nende tugevama regeneratsiooni.

Uued tekkinud rakud asetsesid tavaliselt korrapäraste ridadena paral- 


\section{Mikrofoto 1.}

Päevalille idulehtede lōikepinnalähedased rakud 24 tundi pärast operatsiooni: $a-$ puhetunud rakud.

(Pikilōik. Suurend. 280×.)

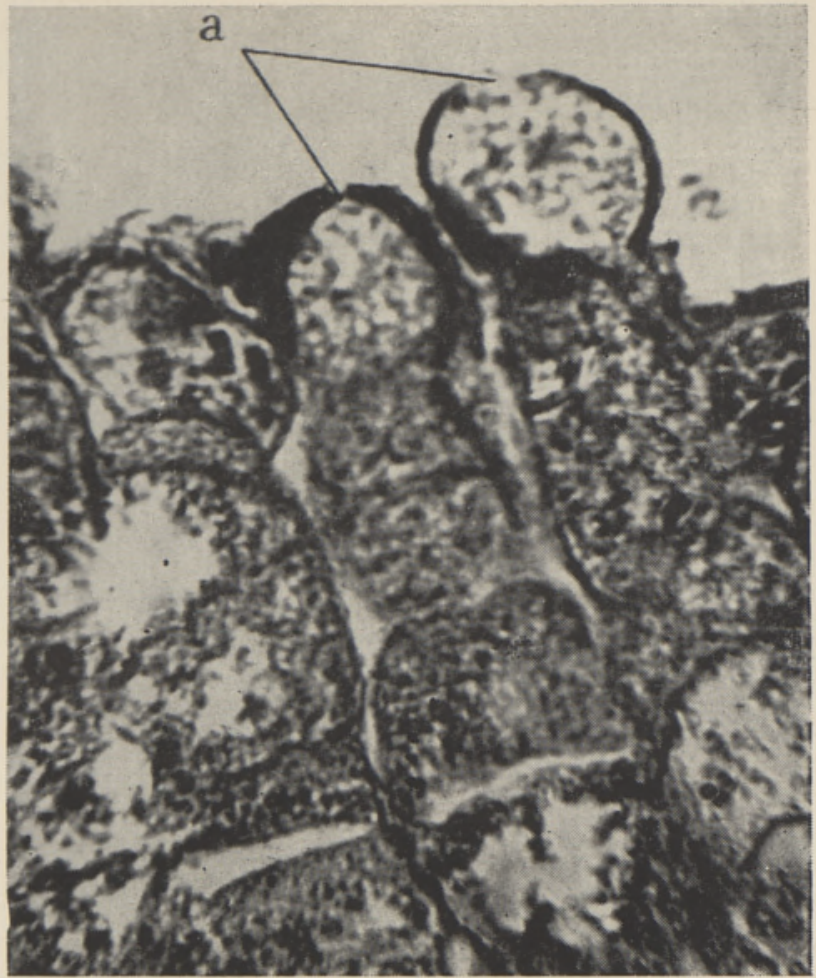

Mikrofoto 2.

Idulehtede lōikepinnalähedased rakud 2 päeva pärast operatsiooni:

$a-$ suurenenud tuumad.

(Pikilōik. Suurend. 280 X.) 


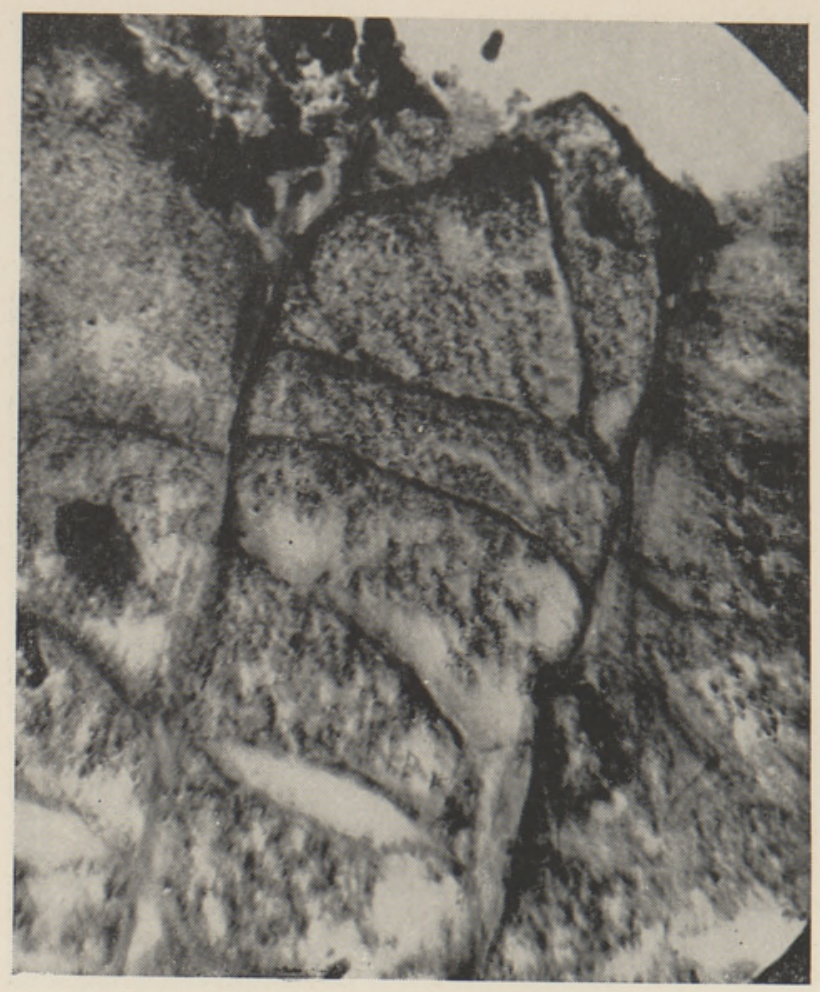

Mikrofoto 3.

Idulehtede lõikepinnalähedased noored rakud.

(Pikilōik. Suurend. $400 \times$.)
Mikrofoto 4 .

Idulehtede lōikepinna ja epidermise vigastusala:

$a$ - kallus lōikepinnal,

$b-$ kallus epidermisel.

(Suurend. $280 \times$.)

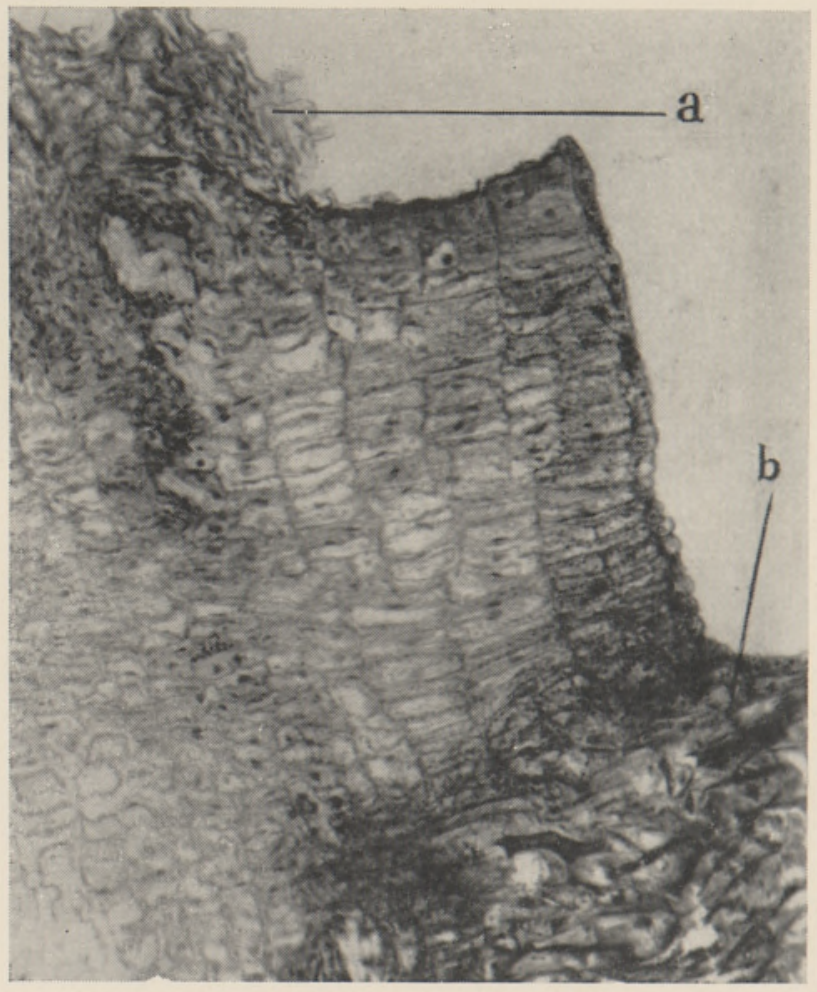


leelselt lõikepinnaga. Vahel märgati rakkude vaheseina teket risti lö̀ikepinnaga (mikrofoto 3). Noored meristeemrakud saavutasid emaraku suuruse ning pooldusid omakorda. Lõikepinna parenhüümrakkude pooldumist võib pidada kalluse tekke esimeseks etapiks. Edasine kalluse areng toimuski nii idulehtede parenhüümrakkude kui ka äsja tekkinud meristeemrakkude pooldumise teel. $17-18$ päeva pärast operatsiooni täheldati kalluse rakkude diferentseerumist. Kallusekühmu äärmistel parenhüümrakkudel paksenes kest, tekkisid vakuoolid ja teralise ehitusega protoplasmas esines rikkalikult plastiide. Kühmu keskel oli üksikuil rakkudel (promeristeemi rakkudel) intensiivne pooldumisvõime, mille tagajärjel tekkis rohkesti meristeemrakke ning need moodustasid kalluses koldeid. Nendest meristeemrakkudest diferentseerusid trahheiidid, mis olid ühenduses idulehe juhtkoega ning varustasid kallust toitainete ja veega.

Idulehtede alumise (liiva sees oleva) osa parenhüümrakud kalluse tekkest otseselt osa ei võtnud. Siia ei ulatunud operatsiooni mõju ning toitained püsisid neis rakkudes kõige kauem. Seetõttu tuli arvata, et ainevahetusprotsessid toimusid siin aeglaselt. Idulehtede parenhüümrakkudest kasutasid toitained järk-järgult ära kalluse rakud. Edasine kalluse suurenenline toimus vaid meristeemrakkude pooldumise teel, seni kuni idulehtedes jätkus toitaineid. Seega sōltus kalluse eksisteerimine idulehtede tagavaraainete hulgast, nagu selgus reaktsioonist $\mathrm{J}+\mathrm{JK}$-ga.

Päevalille idulehtede epidermise ja selle all oleva sammaskoe rakkude vigastamine kutsus esile intensiivse kalluse tekkimise (mikrofoto 4). See asjaolu oli omakorda kinnituseks iduleherakkude suurele potentsiaalsele võimele regenereeruda.

Pimeduses kasvatatud opereeritud idulehed olid kahvatukollased ja nende rakkudes esines rohkesti leukoplaste. Rakud olid suured, korrapäratu kujuga; kallusekühme oli rohkem ja nad olid suuremad.

Tavaliselt 19-21 päeva pärast operatsiooni täheldati kallusekühmus trahheiididelähedaste meristeemrakkude kiireid pooldumisprotsesse. 48 tunni jooksul võis neist formeeruda juurealge, mille edasine areng toimus väga kiirelt: juba paari päeva pärast oli juurte olemasolu ka makroskoopiliselt märgatav. Paljudel juhtudel tekkis $1-2$ juurt korraga ja samal ajal esines kalluse sisemises osas veel meristeemrakkude koldeid, milledest sobivais tingimustes (olemasolevate juurte eemaldamise puhul) võisid omakorda areneda juured. Juured olid tugevad ja $5-7 \mathrm{~cm}$ pikad. Nad tungisid liiva, kust vôtsid vett ja mineraalsooli. Idulehed, milledel ei arenenud juuri, hävisid juba kuu aja pärast.

Valguses kultiveeritud idulehed olid intensiivselt rohelised. Nende ehituses oli märgata kudede täielikumat diferentseerumist, eriti juhtkudede osas. Nii kalluse kui ka lõikepinna lähedased parenhüümrakud olid tihedalt täidetud klorofülliteradega, mistōttu lõikepind paistis rohekana. Rakud olid võimelised iseseisvalt assimileerima. Mõōtmetelt olid valguses kultiveeritud idulehtedel nii kallusekühmud kui ka nende rakud väiksemad. Regeneratsiooniprotsessid toimusid aeglasemalt, kuid idulehed võisid eksisteerida kauem - umbes kolm kuud. Kahe viimase kuu jooksul ei toimunud neis olulisi tsütoloogilis-histoloogilisi protsesse. Rakkude pooldamine aeglustus ja viimaks lakkas. Tavaliselt juuri ei tekkinud ja lõpuks idulehed koos kallusega hävisid.

Kallusekühmude tsütoloogilis-histoloogilistes analüüsides ei täheldatud üh€lgi juhul varre adventiivpungade diferentseerumist sekundaarse meristeemi kolletes. Päevalille idulehed ei olnud võimelised reprodutseerima tervet taime, kui operatsiooni teel eemaldati koos kasvukuhikuga ka selle lähedased primaarse meristeemi aktiivsed rakud, Seda asjaolu võib 
seletada primaarse ja sekundaarse meristeemi erineva potentsiaalse võimega regeneratsiooni- ja reproduktsiooniprotsessideks.

Käesolevast tööst selgus, et päevalille idulehtede rakıd, mis on tagavaraainete panipaigaks, on ühtlasi suure regeneratsioonivõimega.

\section{Kokkuvõte}

1. Pärast päevalille idulehtede opereerimist tekkis nende lõikepinnale alati kallusekühme. Oheaegselt ning samades tingimustes kultiveeritud idulehtedel tekkis kallus eri aegadel. See on seletatav nende kudede erineva kvaliteediga ja mitmesuguste füsioloogiliste erinevustega.

2. Päevalille opereeritud idulehed kasvasid nii parenhüümrakkude mitootilise pooldumise kui ka suurenemise teel.

3. Kalluse teke nii valguses kui ka pimeduses kultiveeritud idu'ehtedel toimus lõikeninnalähedaste parenhüümrakkude mitootilisel pooldımisel, mille tagajärjel tekkisid meristeemrakud. Edaspidine kallusekühmude areng toimus vähem idulehe parenhüümrakkude, kuid intensiivsemalt noorte, äsja tekkinud rakkude pooldumisel.

4. Pimeduses kultiveeritud idulehtedel tekkis suurem kallus, samuti olid nende rakud suuremad valguses kultiveeritud idulehtede omadest. Opereeritud idulehed eksisteerisid valguses kauem, sest nad olid assimilatsioonivõimelisemad; pimeduses hävinesid nad tavaliselt varem.

5. Kallusekühmude keskel formeerus rohkesti meristeemrakkude koldeid, mille diferentseerumisel tekkisid trahheiidid. Trahheiididelähedasist meristeemrakkudest formeerusid juurealgmed. Meristeemrakkude koldeid oli kalluses palju, kuid neist kõigist ei arenenud juuri.

6. Päevalille idulehed ei olnud võimelised reprodutseerima tervet taime, kui operatsiooni teel eemaldati koos kasvukuhikuga ka selle lähedased primaarse meristeemi aktiivsed rakud. Seda asjaolu võib seletada primaarse ja sekundaarse meristeemi erineva potentsiaalse võimega regeneratsiooni- ja reproduktsiooniprotsessideks.

\section{K IR J A N U S}

B lociszewski, Th., 1876. Physiologische Untersuchungen über die Keimung und weitere Entwicklung einiger Samenteile bedecktsamiger Pflanzen. Landwirtsch. Jahrb., Bd. V.

B onnet, Ch., 1779. Recherches sur l'usage des feuilles dans les plantes. V. IV, $\S$ LXXXIX.

$\mathrm{Kabus}$, $\mathrm{Br} .$, 1912. Neue Untersuchungen über Regenerationsvorgänge bei Pflanzen. Cohns. Beitr. z. Biol. d. Pflanzen, 11.

$\mathrm{K}$ ü s t e r, E., 1903. Beobachtungen über Regenerationserscheinungen an Pflanzen. Bot. Zbl., 14. Beih.

$\mathrm{N}$ ĕ m e c, B., 1905. Studien über Regeneration. Berlin.

Něm ec. B., 1911. Weitere Untersuchungen über die Regeneration. Bull. Acad. Sci., Boheme, 3 und 4 .

S i mon. S., 1904. Untersuchungen über die Regeneration der Wurzelspitze. Jahrb. Wiss. Bot., 40. Leipzig.

$\mathrm{S} \mathrm{m}$ ith, L. H., 1907. Beobachtungen über Regeneration und Wachstum an isolierten Teilen von Pflanzenembryon. Autoreferat.

$\mathrm{Z}$ a be 1, N., 1882. Entwicklung der von der Achse abgetrennten Keimblätter. Moscau. $\mathrm{V}$ a n Tieghem, Ph., 1873. Recherches Physiologiques sur la Germination. Annales des Sciences Naturelles, Ser. 5, XVII.

V öchting, H., 1878, 1884. Uber Organbildung im Pflanzenreich. I, II.

М а к с и м о в Н. А., 1946. О механизме действия ростовых веществ на растительные клетки. Бюлл. Моск, об-ва испыт. природы, отд. биол., 51 (2). 
М и х а й л о в О. Ф., 1951. Морфогенез новообразований подсолнечника и гороха, полученных из нзолированных семядолей и зародышей, лишенных семядолей. Рукопись диссертации. Л.

М и х а й ло в О. Ф., 1952. Биологическая специфнка семядолей в семенах растений, не сохраняющих эндоспермы. Сб. «Научные труды, посвященные 150-летию Тартуского государственного университета». Таллин.

Ми х а йлов О. Ф., 1957а. Методы культуры тканей и получение новых форм растений. Уч. зап. ТГУ. Сб. трудов ест.-мат. факультета, № 46, Серия биологическая.

М и х а й л ов О. Ф., 1957b. К вопросу о филогенетическом значении явлении регенерации у растений. Уч. зап. ТГУ. Сб. трудов ест.-мат. факультета, № 46, Серия биологическая.

Н а в а ш и н М. С., 1936. Методика цитологического исследования для селекционных целей. ОГиз. Сельхозгиз.

Tartu Riiklik Olikool

Saabus toimetusse

15. III 1958

\title{
О ЦИТО-ГИСТОЛОГИЧЕСКИХ ОСОБЕННОСТЯХ ВОЗНИКНОВЕНИЯ И ДИФФЕРЕНЦИАЦИИ КЛЕТОК КАЛЛЮСА
}

\author{
А. Ю. Тоомсалу, \\ кандидат биологических наук
}

л. Я. Ярвекюльг

Резюме

Задача настоящей работы состояла в изучении процесса каллюсообразования и дифференциации каллюсных клеток на изолированной семядоле Helianthus annuus L., сорта Саратовский 169. Выбор объекта исследования и проведение самого цито-гистологического анализа обусловливались имеющими в данном случае место формообразовательными процессами in vitro. Изолированные семядоли культивировались в стерильных условиях при температуре $15-25^{\circ} \mathrm{C}$ в двух вариантах: в темноте и при восьмичасовом ежесуточном освещении люминесцентными лампами. Фиксация материала

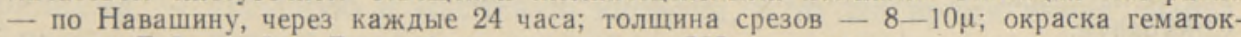
силином Гейденгайна. Всего было исследовано 228 препаратов.

Цито-гистологический анализ показал, что вблизи поверхности среза процесс регенерации начинается с увеличения объема паренхимных клеток семядоли и последующего митотического деления их. Возникшие таким образом молодые клетки меристематического типа достигают величины материнской клетки и делятся в свою очередь путем митоза. Очень скоро эти меристематические клетки вновь превращаются в паренхиму, получившую название каллюсной, которая и образует макроскопически видимый бугорок каллюса. Внутри каллюса, однако, имеет место сохранение отдельных клеток активной, интенсивно делящейся меристемы, образующей своеобразные очаги. Именно в этих меристематических очагах наблюдается дифференциация трахеид, постепенно соединяющихся с проводящей системой семядоли.

Обычно через 19-21 день после операции у изолированных семядолей, культивируемых в темноте, наблюдается особо интенсивное деление меристематических клеток вблизи трахеид, ведущее к дифференциации корневой почки. Весь процесс заложения корневого зачатка происходит в течение около 48 часов. Семядоли, росшие в темноте, были сильно этиолированы. Клетки их достигали больших размеров, были различной формы и содержали лейкопласты. В световом варианте имело место только образование небольшого каллюса, состоящего из сравнительно мелких клеток. Сами семядоли содержали большое количество хлорофилла.

При цито-гистологических анализах каллюсовых бугорков у изолированных семядолей, культивируемых в наших условиях, дифференциации стеблевых почек не отмечалось. По-видимому, семядоля подсолнечника может репродуцировать весь зародыш только при условии сохранения во время операции части наиболее активной первичной меристемы. 


\title{
UBER DIE ZYTO-HISTOLOGISCHE EIGENART DER KALLUSZELLEN UND IHRE DIFFERENZIERUNG
}

\author{
A. Toomsalu, L. Järvekülg
}

\section{Zusammenfassung}

Aufgabe dieser Arbeit war die Untersuchung der Kallusbildung und der Differenzierung der Zellen des Kallus am isolierten Keimblatt der Sonnenblume (Helianthus annuus L.. Sorte 'Saratow 169'). Die Arbeit bestand in der Züchtung von isolierten Keimblättern der Sonnenblume in vitro, sowie in entsprechenden zyto-histologischen Analysen, worüber sich im einsch!ägigen Schrifttum nur unzulängliche Angaben finden. Die isolierten Keimblätter wurden unter sterilen Bedingungen bei einer Temperatur von $15-25^{\circ} \mathrm{C}$ in zwei Varianten gezüchtet, wobei der eine Teil sich ständig im Dunkeln befand. während der andere täglich acht Stunden lang durch Lumineszenzlamnen bestrahlt wurde. Die Fixation des Materials erfolgte alle 24 Stunden, nach Nawaschin, die Dicke der Schn'tte betrug 8-10 $\mu$. Zur Färbung diente Heidenhainsches Hämatoxylin. Insgesamt wurden 228 Präparate untersucht.

Die zvto-histologischen Analysen ergaben. dass der Regenerationsprozess nahe der Schnittoberfläche mit der Vergrösserung des Umfanges der Parenchvmzellen des Keimblattes und ihrer darauffolgenden mitotischen Teilung einsetzt. Die auf die beschriebene Art entstandenen jungen Zellen von meristematischem Charakter erreichen die Grösse der Mutterzelle und teilen sich ihrerseits durch Mitose. Sehr bald differenzieren sich diese meristematischen Zellen aufs neue und wandeln sich in parenchymatöse um, die die makroskopisch sichtbare Ausbuchtung des Kallus bilden. Im Inneren des Kallus bleiben jedoch einige aktive, sich intensiv teilende meristematische Zellen bestehen, die dort eigenartige Herde bilden. Gerade in diesen meristematischen Herden ist die Dilferenzierung von Tracheiden zu beobachten, die sich allmählich mit dem Leitungssystem des Keimblattes vereinigen.

Meistens am 19,-21. Tage nach der Operation lässt sich bei den im Dunkeln gezüchteten isolierten Keimblättern eine besonders intensive Teilung der meristematischen Zellen in der Nähe der Tracheiden verfolgen, was zur Differenzierung der Wurzelknospe führt. Insgesamt dauert der Prozess der Entstehung der Wurzelanlage etwa 48 Stunden. Durch die Dunkelheit bedingt, waren die Keimblätter stark etioliert. Ihre Zellen waren grösser als gewöhnlich, sie waren von verschiedener Form und enthielten Leukoplasten. Bei der bestrahlten Variante kam es lediglich zur Bildung eines kleineren Kallus, der aus verhältnismässig kleinen Zellen bestand. Die Keimblätter selbst enthielten reichlich Chilorophyll.

Bei der zyto-histologischen Untersuchung der Kallusausbuchtungen an Keimblättern, die unter den erwähnten Bedingungen gezüchtet worden waren, liess sich ke'ne Differenzierung von Adventivknospen des Stengels feststellen. Offenbar ist das Keimblatt der Sonnenblume nur dann imstande, den ganzen Keim zu reproduzieren, wenn bei der Operation ein Teil des aktiveren primären Meristems erhalten bleibt. 